\title{
Gut Bacteria of Columbia livia Are a Potential Source of Anti-Tumour Molecules
}

\author{
Morhanavallee Soopramanien¹, Naveed Ahmed Khan²*, Bibi Noorheen Haleema \\ Mooneerah Neerooa ${ }^{1}$, Kuppusamy Sagathevan ${ }^{1}$, Ruqaiyyah Siddiqui $^{3}$
}

\begin{abstract}
Objectives: The overall aim was to determine whether gut bacteria of Columbia livia are a potential source of antitumour molecules. Methods: Faecal and gut microbiota of Columbia livia were isolated, identified and conditioned media were prepared containing metabolites. Growth inhibition, lactate dehydrogenase cytotoxicity and cell survival assays were accomplished against cervical cancer cells. Next, liquid-chromatography mass spectrometry was conducted to elucidate the molecules present. Results: A plethora of bacteria from faecal matter and gastrointestinal tract were isolated. Selected conditioned media exhibited potent anticancer effects and displayed cytotoxicity to cervical cancer cells at $\mathrm{IC}_{50}$ concentration of 10.65 and $15.19 \mu \mathrm{g} / \mathrm{ml}$. Moreover, cells treated with conditioned media exhibited morphological changes, including cell shrinking and rounding; indicative of apoptosis, when compared to untreated cells. A total of 111 and 71 molecules were revealed from these gut and faecal metabolites. The identity of 60 molecules were revealed including, dihydroxymelphalan. Nonetheless, 122 molecules remain unidentified and are the subject of future studies. Conclusion: These findings suggest that gut bacteria of Columbia livia possess molecules, which may have anticancer activities. Further in silico testing and/or high throughput screening will determine potential anticancer properties of these molecules.
\end{abstract}

Keywords: Rock pigeon- Columba livia domestica- gastrointestinal microbiota- anticancer

Asian Pac J Cancer Prev, 22 (3), 733-740

\section{Introduction}

Cancer remains a leading cause of mortality worldwide despite advances in the development of innovative therapeutic options, such as chemotherapy, radiation therapy, stem cell therapy, immunotherapy, targeted therapy, hormone therapy and surgery (Khan et al., 2019; Chakraborty and Rahman, 2012), suggesting the need to identify novel therapeutic agents. Notably, species such as crocodiles live in environments laden with heavy metals, feed on rotten meat, often tolerate high levels of radiation, are long-lived but rarely reported to develop cancer (Jeyamogan et al., 2017; 2019; Siddiqui et al., 2017; Siddiqui et al., 2016). Other species such as cockroaches exhibit high radiation resistance (lethal dose is 15 times higher than for humans) (Mosaheb et al., 2018; Soopramanien et al., 2019). Thus it is interesting to understand the mechanisms by which such hardy species are able to endure carcinogenic agents that are detrimental to humans. In support, our previous studies have shown that gut bacteria of crocodiles, water monitor lizard and scorpion possess potential anticancer molecules (Mosaheb et al., 2018; Soopramanien et al., 2019; Heyde and Ruder,
2015). For the first time, here we tested gut bacteria of pigeon (Columbia livia) for antitumour effects.

\section{Materials and Methods}

\section{Ethics committee approval}

Ethics approval was obtained from Sunway Research Ethics Committee (Research Ethics Approval Code: PGSUNREC 2019/023). The animal was procured from the wild, species identified, handled, and dissected by qualified zoologist, Dr K Sagathevan who routinely performs such procedures.

\section{Gut and Faecal sample collection}

The gastrointestinal tract was carefully removed and opened with a longitudinal incision. The gut bacteria were isolated using sterile cotton swabs and were then inoculated on nutrient agar and blood agar plates. Bacteria from the faeces were isolated using sterile cotton swab and plated as mentioned above. Plates were incubated overnight at $37^{\circ} \mathrm{C}$ and bacterial colonies were subjected to identification as described previously (Soopramanien et al., 2019; Akbar et al., 2018). 


\section{Bacterial identification}

Bacterial identification was carried out based on their texture, size, colour, and shape and inoculating them onto separate fresh nutrient agar plates which were successively incubated overnight at $37 \mathrm{oC}$. Bacteria were subcultured until agars with pure cultures were obtained. Pure bacteria were subjected to Gram staining. Next, bacterial identification was conducted using Analytical profile index (API) identification strip; API 20E was used for gram-negative bacteria while API staph was used for gram-positive bacteria as described previously (Soopramanien et al., 2019; Akbar et al., 2018).

\section{Conditioned medium (CM) preparation}

Pure bacterial cultures were inoculated in RPMI-1640 were incubated for $48 \mathrm{~h}$, at $37^{\circ} \mathrm{C}$. Following incubation, bacterial cultures were centrifuged at $4^{\circ} \mathrm{C}, 10,000 \mathrm{x} \mathrm{g}$, for $1 \mathrm{~h}$. Supernatant were collected and filtered using sterile $0.22 \mu \mathrm{m}$ pore size cellulose acetate syringe filter, also referred to $\mathrm{CM}$ (conditioned media). The $\mathrm{CM}$ were quantified for protein estimation using Bradford assay and then stored at $-80^{\circ} \mathrm{C}$ (Soopramanien et al., 2019; Akbar et al., 2018).

\section{Culture of cancer and normal cells}

The cancer cells used in this study were Cervical cancer (HeLa (ATCC ${ }^{\circledR}$ CCL2 $\left.{ }^{\mathrm{TM}}\right)$ ), breast cancer (MCF7 $\left(\right.$ ATCC $\left.^{\circledR} \mathrm{HTB}-22^{\mathrm{TM}}\right)$ ) and prostate cancer (PC3 (ATCC ${ }^{\circledR}$ CRL1435 ${ }^{\mathrm{TM}}$ )) and normal cell line; aneuploid immortal keratinocyte (HaCaT). Cells were cultured in RPMI-1640 augmented with $10 \%$ foetal bovine serum (FBS), 1\% L-glutamine, $1 \%$ penicillin streptomycin antibiotic and 1\% Minimum Essential Media (MEM) Non-Essential amino acid at $37 \mathrm{oC}$ with $5 \%$ carbon dioxide and $95 \%$ humidity (Soopramanien et al., 2019; Akbar et al., 2018).

\section{Growth inhibition assays}

Assays to determine inhibition of growth was performed as previously described. Briefly, cells were grown in 96-well plates until 50\% confluency was reached. Control wells were trypsinised to determine the cell count, while experimental wells were treated with $\mathrm{CM}$ prepared from bacteria isolated from both faeces and gut of $\mathrm{C}$. livia. CM from E. coli K-12 (a non-pathogenic laboratory strain) was used as negative control. The treated cells were incubated at $37 \mathrm{oC}$ in a $5 \% \mathrm{CO}_{2}$ with $95 \%$ humidity, until the untreated cells became $100 \%$ confluent. The cells were then trypsinised with $2.5 \%$ trypsin for 15 min and subjected to Trypan blue exclusion assay using a haemocytometer. The growth inhibition effects were established by comparing the number of viable cells of untreated cells (control) and treated cells. To confirm the anticancer activity of the CM, selected CM were concentrated using vacuum concentrator. $\mathrm{CM}$ were then quantified through Bradford assay as described above and used for growth inhibitory assays at a concentration of $10 \mu \mathrm{g} / \mathrm{ml}$.

\section{Cytotoxicity assays, cell staining and survival assays}

Cells were grown to confluency in 96-wells plates. Next, cells were treated with $\mathrm{CM}$ prepared from bacteria isolated from faeces and gut of C. livia for $24 \mathrm{~h}$ at $37^{\circ} \mathrm{C}$ in a $5 \% \mathrm{CO}_{2}$ with $95 \%$ humidity. CM from E. coli $\mathrm{K}-12$ was used as negative control, while the positive control was prepared by treating control cells with $0.2 \%$ Triton X-100 for $30 \mathrm{~min}$ at $37^{\circ} \mathrm{C}$, to induce $100 \%$ cell death. Next, the supernatants were collected and lactate dehydrogenase release was determined using cytotoxicity detection kit. The percentage cytotoxicity was calculated as follows:

$\%$ cytotoxicity $=(($ Absorbancesample Absorbancenegative control)/ (Absorbancepositive control - Absorbancenegative control)) X 100, whereby the negative control comprised of cells treated with RPMI-1640 media only, and the positive control contained cells treated with the detergent: Triton X-100.

Moreover, cell staining was performed. Briefly, cells were fixed with $100 \%$ acetone and $100 \%$ methanol in a $1: 1$ ratio for $15 \mathrm{~min}$ and stained with $0.4 \%$ Trypan blue for $15 \mathrm{~min}$. Plate was dried and pictures of individual wells were captured. Cell survival assay was also conducted to determine viability of cells treated with CM. Briefly, cells treated with $\mathrm{CM}$ were collected and seeded onto new plates containing growth media for $24 \mathrm{~h}$ at $37^{\circ} \mathrm{C}$ in a $5 \% \mathrm{CO}_{2}$ with $95 \%$ humidity, and their re-growth were examined using a light microscope (Soopramanien et al., 2019; Akbar et al., 2018).

\section{S rDNA sequencing of bacteria with active CM}

Selected bacteria that exhibited activity were subjected to $16 \mathrm{~S}$ rDNA sequencing. Bacteria were grown in nutrient broth at $37^{\circ} \mathrm{C}$ with constant shaking. Bacteria were then pelleted by centrifugation and subjected to DNA extraction using QIAGEN DNA extraction kit, as detailed in the manufacturer's instructions (Akbar et al., 2019). The extracted bacterial DNA was amplified using 16S amplification using Taq DNA Polymerase 2X-preMix and a pair of $16 \mathrm{~S}$ rDNA Universal primers; $27 \mathrm{~F}$ (5'-AGAGTTTGATCCTGGCTCAG-3') forward primer and 1492R (5'-GGTTACCTTGTTACGACTT-3') reverse primer, with conditions: 1 cycle at $95 \mathrm{oC}$ for 5 minutes, amplification step; 30 cycles (i) $95^{\circ} \mathrm{C}$ for 30 seconds, (ii) $55^{\circ} \mathrm{C}$ for 30 seconds, and (iii) $72^{\circ} \mathrm{C}$ for 1 minute and final step; 1 cycle at $72^{\circ} \mathrm{C}$ for 5 minutes. Gel electrophoresis was conducted using $1 \%$ agarose gel in $1 x$ Tris-acetateEDTA (TAE) buffer at $100 \mathrm{~V}$ for $40 \mathrm{~min}$. Amplified DNA was sequenced via Sanger sequencing. The nucleotide sequences obtained were aligned using ChromasPro software and were then blasted into the National Center for Biotechnology Information (NCBI) database for Standard Nucleotide BLAST, for 16S RNA sequences, to obtain the identity of the bacteria with maximum percentage nucleotide match (Akbar et al., 2019).

\section{$I C_{50}$ determination of active CM through MTT cell viability assay}

The $\mathrm{IC}_{50}$ value of active $\mathrm{CM}$ was determined using MTT (3-(4,5-dimethylthiazol-2-yl)-2,5-diphenyltetrazolium bromide) assay as previously described by (Akbar et al., 2019). Briefly, cells were grown to $70 \%$ confluency in 96-wells plates and treated with active $\mathrm{CM}$ at various concentrations; 2.5, 5.0, 10 and $20 \mu \mathrm{g} / \mathrm{ml}$ in growth medium. Post incubation, positive control cells were 
treated with $0.2 \%$ Triton $\mathrm{X}-100$ for $30 \mathrm{~min}$ at $37^{\circ} \mathrm{C}$, to induce $100 \%$ cell death. The percentage cell viability was calculated as follows:

$\%$ Cell viability $=[($ Absorbance sample - Absorbance blank)/ (Absorbance negative control - Absorbance blank)] X 100

Identification of molecules(s) exhibiting anticancer activity through Liquid chromatography-mass spectrometry (LC-MS)

Active CM were subjected to LC-MS analysis as described previously (Ali et al., 2017). Molecules were extracted from active $\mathrm{CM}$ through solvent extraction using chloroform in 1:3 ratio of chloroform to $\mathrm{CM}$. The molecules dissolved in chloroform were subjected to evaporation and resuspended in 1:1 ratio of methanol to type 1 water. The samples were subjected to Agilent 1290 Infinity LC system coupled to Agilent 6520 Accurate-Mass Q-TOF mass spectrometer with dual ESI. The molecules were separated through Agilent Zorbax Eclipse XDB-C18 column with a particle size of 3.5 micron and Narrow-Bore of 2.1x150mmat 25oC using solvent A ( $0.1 \%$ formic acid in water) and solvent B $(0.1 \%$ formic acid in Acetonitrile) for a total run time of 30 minutes. The separated molecules were then ionized by means of ESI + jet stream ion mode with the QQQ analyzer, with parameters: capillary voltage at $4500 \mathrm{~V}$, sheath gas flow at $8 \mathrm{~L}$ per min, fragmentor voltage 135 $\mathrm{V}$, gas temperature at $350^{\circ} \mathrm{C}$, gas flow at $8 \mathrm{~L}$ per min, and nebulizer gas at $40 \mathrm{psi}$ and detector used was MCP
Microchannel Plate detector, while the blank expended after each sample was of composition $50 \% \mathrm{MeOH}+$ $50 \%$ MiliQ water. Chromatogram were generated from LC-MS which were used to determine the identity of the molecules from the Metlin_AM_PCDL-N-170502.cdb database. SciFinder database was then used to determine whether the identified molecules had previously reported biological activities.

\section{Results}

Various bacteria were isolated from faeces and gastrointestinal tract of C. livia

Several Gram-positive and Gram-negative bacteria were isolated from the faeces and gastrointestinal tract of C. livia (Table 1). Gram-positive bacteria isolated were coagulase negative Staphylococcus spp., Gram positive bacilli, and Lysinibacillus boronitolerans, while the Gramnegative bacteria were Escherichia coli, and Pseudomonas aeruginosa. While from the gastrointestinal tract, Grampositive bacteria; Gram positive bacilli, Lysinibacillus fusiformis, Lysinibacillus boronitolerans, coagulase negative Staphylococcus spp., Lysinibacillus sphaericus, Streptococcus group B, and Streptococcus saprophyticus and Gram-negative bacteria were Escherichia coli, and Sphingobacterium multivorum. As CLF05 and CLG01 showed potent activity, $16 \mathrm{~S}$ rDNA sequencing was performed on these two bacteria. The result revealed that CLF05 and CLG01 are Bacillus cereus ATCC 14579 and Bacillus velezensis strain FZB42, respectively (Table 1).

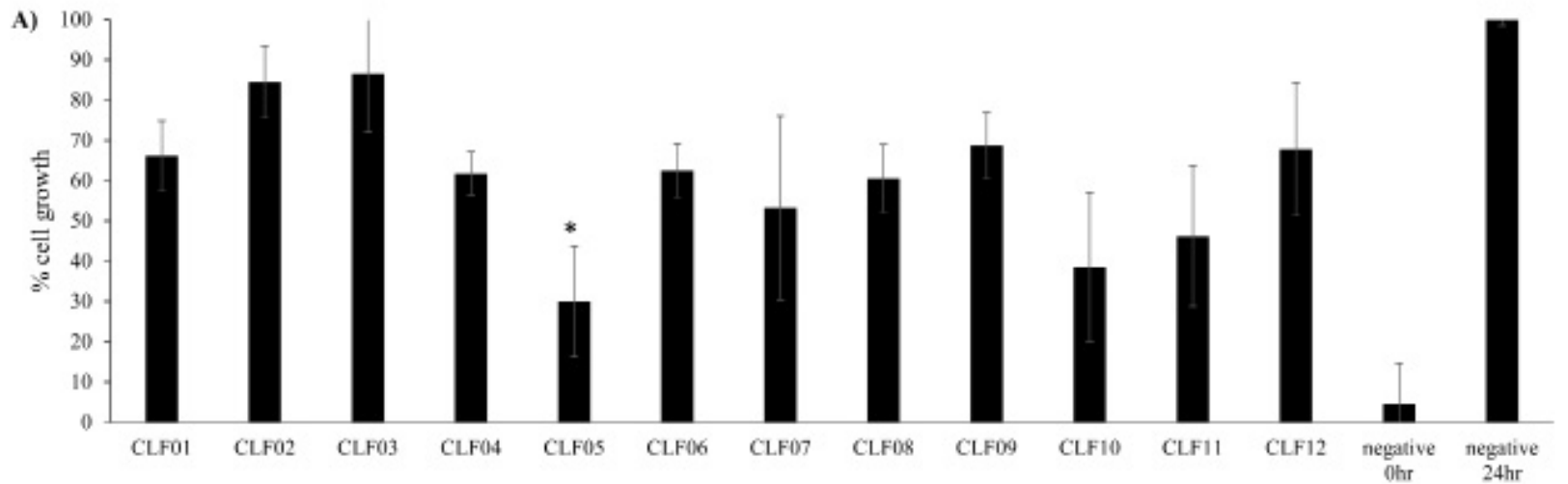

B)

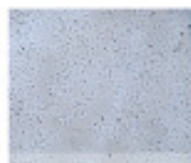

CL.FOI

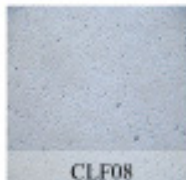

CLF08
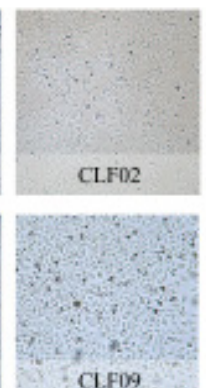
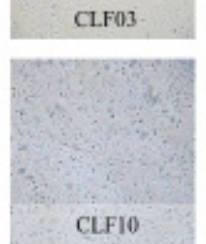
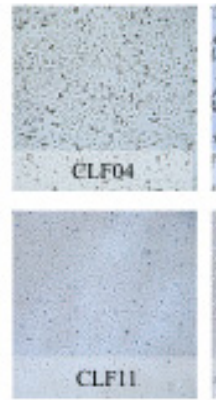
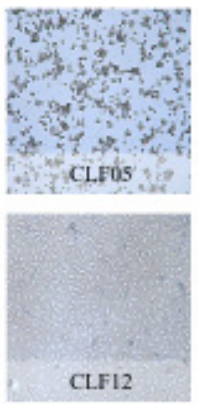

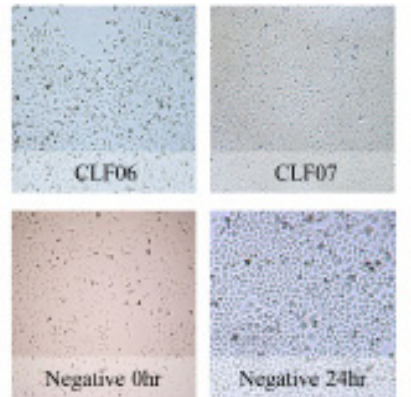

Figure 1. Growth Inhibition Effect of Conditioned Media (CM) Prepared from Bacteria Isolated from the Faecal Sample of Pigeon against HeLa Cells. A) Semi-confluent HeLa cells were incubated with CM and growth inhibition was determined as described in Materials and Methods. B) Using an inverted microscope, images of the cells were taken at $\mathrm{x} 250$. The results are representative of several experiments performed in duplicate. $\mathrm{P}$ value was determined using two sample T-test, two-tailed distribution, $(*)$ is $<0.05$. Negative control $(0 \mathrm{~h})$ is number of cells at the beginning of experiment, while negative control $(24 \mathrm{~h})$ is untreated cells. The data are compared between negative control (24h) and CLF/CLG. Detailed CLF and CLG nomenclature is described in Table 1. 
Table 1. The Bacteria Species Isolated from the Faeces and Gastrointestinal Tract of pigeon

\begin{tabular}{|c|c|c|}
\hline & Gram stain & Bacteria \\
\hline \multicolumn{3}{|c|}{ Pigeon faecal } \\
\hline CLF01 & Gram-negative & Escherichia coli \\
\hline CLF02 & Gram-positive & Coagulase Negative Staphylococcus spp \\
\hline CLF03 & Gram-negative & Escherichia coli \\
\hline CLF04 & Gram-positive & Gram positive bacilli \\
\hline CLF05 & Gram-positive & Gram positive bacilli \\
\hline CLF06 & Gram-positive & Lysinibacillus boronitolerans \\
\hline CLF07 & Gram-negative & Escherichia coli \\
\hline CLF08 & Gram-negative & Escherichia coli \\
\hline CLF09 & Gram-negative & Escherichia coli \\
\hline CLF10 & Gram-negative & Pseudomonas aeruginosa \\
\hline CLF11 & Gram-negative & Escherichia coli \\
\hline CLF12 & Gram-negative & Escherichia coli \\
\hline \multicolumn{3}{|l|}{ Pigeon gut } \\
\hline CLG01 & Gram-positive & Gram positive bacilli \\
\hline CLG02 & Gram-positive & Lysinibacillus fusiformis \\
\hline CLG03 & Gram-positive & Gram positive bacilli \\
\hline CLG04 & Gram-positive & Lysinibacillus boronitolerans \\
\hline CLG05 & Gram-negative & Escherichia coli \\
\hline CLG06 & Gram-positive & Coagulase Negative Staphylococcus spp \\
\hline CLG07 & Gram-positive & Lysinibacillus sphaericus \\
\hline CLG08 & Gram-positive & Lysinibacillus sphaericus \\
\hline CLG09 & Gram-positive & Gram positive bacilli \\
\hline CLG10 & Gram-positive & Lysinibacillus boronitolerans \\
\hline CLG11 & Gram-positive & Lysinibacillus fusiformis \\
\hline CLG12 & Gram-positive & Lysinibacillus fusiformis \\
\hline CLG13 & Gram-negative & Escherichia coli \\
\hline CLG14 & Gram-negative & Escherichia coli \\
\hline CLG15 & Gram-negative & Escherichia coli \\
\hline CLG16 & Gram-positive & Lysinibacillus sphaericus \\
\hline CLG17 & Gram-positive & Streptococcus group B \\
\hline CLG18 & Gram-negative & Sphingobacterium multivorum \\
\hline CLG19 & Gram-positive & Streptococcus saprophyticus \\
\hline CLG20 & Gram-positive & Coagulase negative staphylococcus aureus \\
\hline
\end{tabular}

\section{CM from faecal sample of C. livia inhibited HeLa cell growth}

CLF05, CLF07, CLF10 and CLF12 prepared from Bacillus cereus, E. coli, P. aeruginosa and E. coli, inhibited growth of HeLa by 70.0, 46.8, 61.5 and $53.7 \%$ respectively (Figure 1A). While remaining $\mathrm{CM}$ affected the cellular growth of HeLa by less than $40 \%$. CLF01, CLF02, CLF03, CLF04, CLF06, CLF08, CLF09 and
CLF11 showed 66.1, 84.5, 86.5, 61.8, 62.5, 60.5 and $67.8 \%$ HeLa cell growth respectively. The microscopic images supported the graphical representation of results (Fig. 2B). Moreover, CLF05 affected the morphology of HeLa cells as compared to the negative control cells.

\section{CM from gastrointestinal of C. livia inhibited the growth of HeLa cells \\ CLG01, CLG07, CLG17 and CLG18 prepared from} Bacillus velezensis, L. sphaericus, Streptococcus group $\mathrm{B}$ and S. multivorum inhibited growth of HeLa cells by $56.5,43.0,59.8$ and $47.3 \%$ respectively (Figure $2 \mathrm{~A}$ ). However, CLG02, CLG03, CL04, CLG05, CLG06, CLG08, CLG09, CLG10, CLG11, CLG12, CLG13, CLG14, CLG15, CLG16, CLG19 and CLG20 showed $75.2,64.6,6.3,81.2,64.1,78.9,100,100,78.5,86.3$, $96.7,100,82.6,100,60.4$ and $70.6 \%$ HeLa cell growth respectively. Moreover, the microscopic images depicted similar results as the graphical representation (Figure 2B).

\section{CLG01 and CLF05 produced damage to HeLa cells}

Microscopic images for HeLa cells treated with CLF05 showed change in morphology and the cells appeared round, as compared to untreated cells (negative control), albeit no LDH release was determined. In contrast, CM for faeces depicted morphology similar to the negative control. Additionally, wells containing cells treated with CLF05 remained stained similar to the positive control.

\section{Concentrated CM inhibited growth of cancer and normal cells}

At a concentration of $10 \mu \mathrm{g} / \mathrm{ml}$, CLF05 inhibited growth of HeLa, MCF-7, PC3 and HaCaT cells by 100, $100,90.4$ and $82.8 \%$ respectively, while CLG01 inhibited growth of aforementioned cells by 100, 91.6, 80.0 and $35.1 \%$ respectively (Figure 3). The quantitative data were further supported by microscopic images obtained post-treatment of normal and cancer cells. MTT assay results revealed that CLF05 and CLG01 affected viability of HeLa cells at an $\mathrm{IC}_{50}$ concentration of 10.65 and 15.19 $\mu \mathrm{g} / \mathrm{ml}$ respectively (Figure 4 ).

\section{CLF05 and CLG01 possess 111 and 71 molecules}

CLF05 and CLG01 were subjected to LC-MS. Figure 6 shows spectra (negative and positive ion polarity) of molecules detected from CLF05 and CLG01. A total of 111 molecules were detected from CLF05, out of which 54 molecules were identified (Table 2 and Supplementary Table 1), while the remaining molecules are unidentified and potentially novel. Moreover, out of the 54 identified

Table 2. The Molecules Detected, Identified and Unidentified from the Conditioned Media Prepared from Bacteria Isolated from the Faecal Matter and Gastrointestinal Tract of C. livia through LC-MS. The conditioned media prepared were subjected to chloroform extraction and the extracts were subject to LC-MS analysis. The spectre generated were searched in the METLIN library in order to reveal the potential identity of the detected molecules. To assess whether those identified molecules had previously reported biological activity, they were searched in the SciFinder database.

\begin{tabular}{lccccc}
\hline Bacteria & \multicolumn{5}{c}{ Number of molecules } \\
& Detected & Identified & Reported activity & Anticancer activity & Unidentified \\
\hline Bacillus cereus (CLF05) & 111 & 54 & 18 & 1 Dihydroxymelphalan & 57 \\
Bacillus velezensis (CLG01) & 71 & 6 & 1 & - & 65 \\
\hline
\end{tabular}




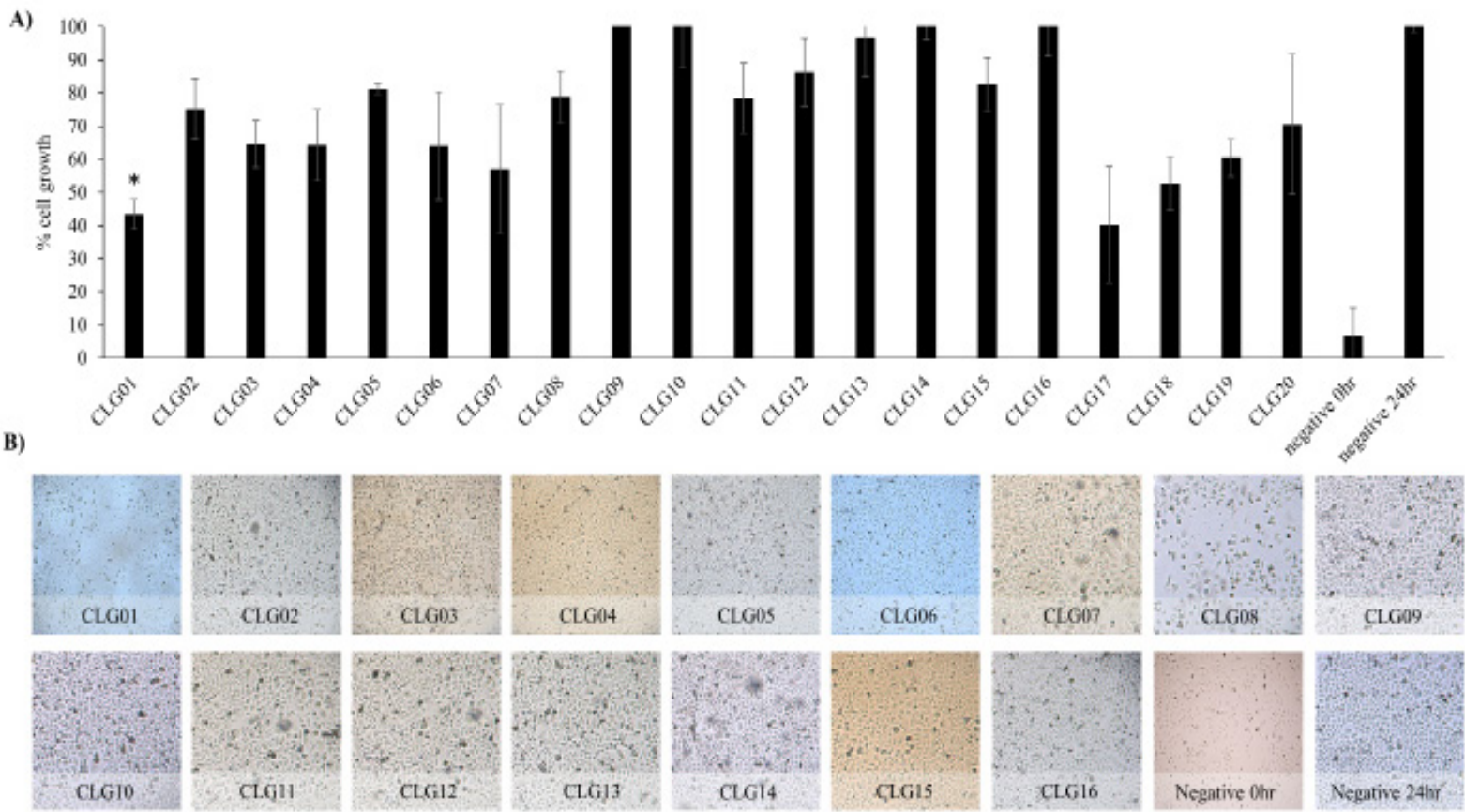

Figure 2. Growth Inhibition Effect of CM Prepared from Bacteria Isolated from the Gastrointestinal Ttract of Pigeon against HeLa cells. A) Semi-confluent HeLa cells were incubated with CM and growth inhibition was determined as described in Materials and Methods. B) Using an inverted light microscope, images of the cells were taken at $\mathrm{x} 250$. The results are representative of several experiments performed in duplicate. $\mathrm{P}$ value was determined using two sample T-test, two-tailed distribution, $(*)$ is $<0 \cdot 05$. Negative control $(0 \mathrm{~h})$ is number of cells at the beginning of experiment, while negative control $(24 \mathrm{~h})$ is untreated cells. The data are compared between negative control $(24 \mathrm{~h})$ and CLF/CLG. Detailed CLF and CLG nomenclature is described in Table 1.

molecules, only 18 had reported biological activity (Supplementary Table 1) while one molecule had reported anticancer effects; namely dihydroxymelphalan. The remaining 57 unidentified molecules from CLF05, had limited information including retention time, molecular mass, and molecular formula (Supplementary Table 2). For CLG01, a total of 71 molecules were detected from HSG16, out of which 6 molecules were identified
(Table 2 and Supplementary Table 1), while the remaining molecules are unidentified. Out of 6 identified molecules, one molecule had reported biological activity (Supplementary Table 1) and none had reported anticancer activity. The remaining 65 unidentified molecules from CLG01 depicted limited information including retention time, molecular mass, and molecular formula (Supplementary Table 2).

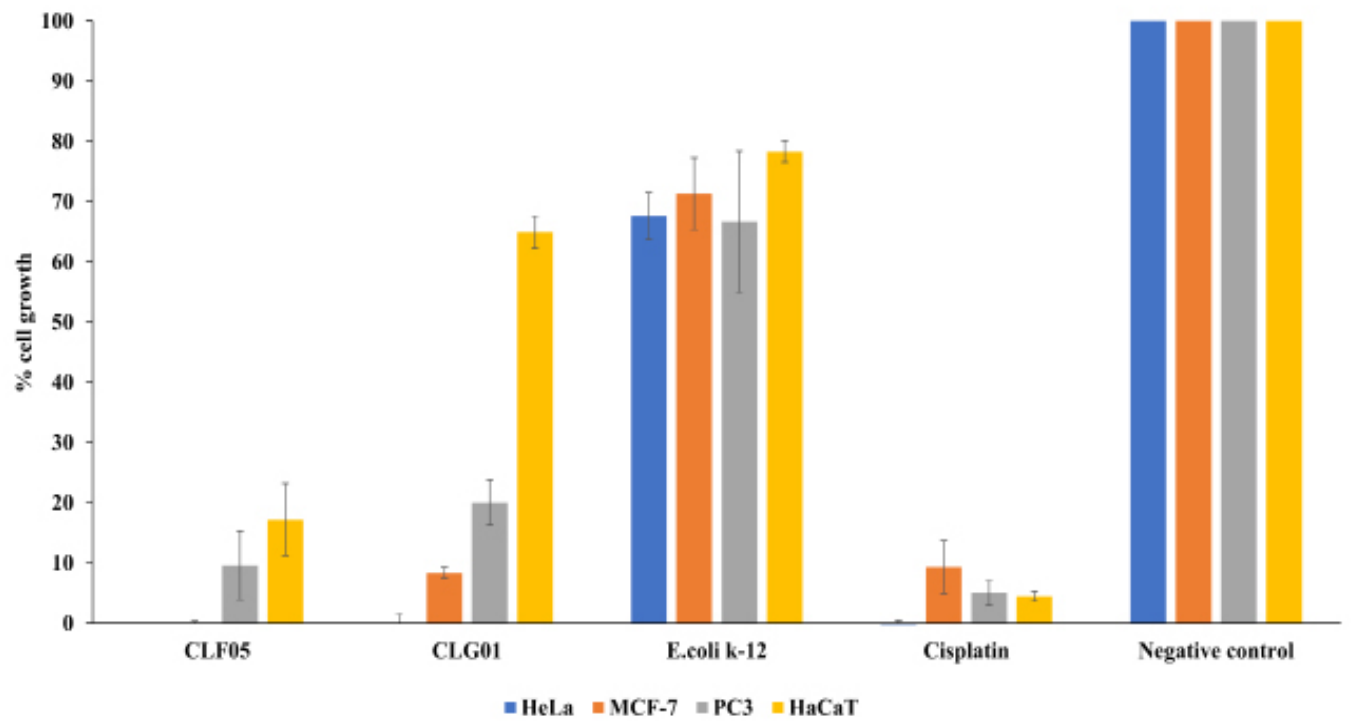

Figure 3. CLF05 and CLG01 Exhibited Effects against Cells at 10 $\mu \mathrm{g} / \mathrm{ml}$. A) Semi-confluent HeLa, MCF-7, PC3 and $\mathrm{HaCaT}$ cells were incubated CLF05 and CLG01 as described in Materials and Methods. Untreated cells were considered as 100\% and effects of CLF05 and CLG01 are presented as relative change. The results are representative of several experiments performed in duplicate. Note that CLG01 exhibited potent effects against all cancer cell lines tested, except normal Hacat cells; while CLF05 showed effects against all cells tested. Control CM from E. coli K-12 showed no effects against any of the cell lines tested. 
$A$

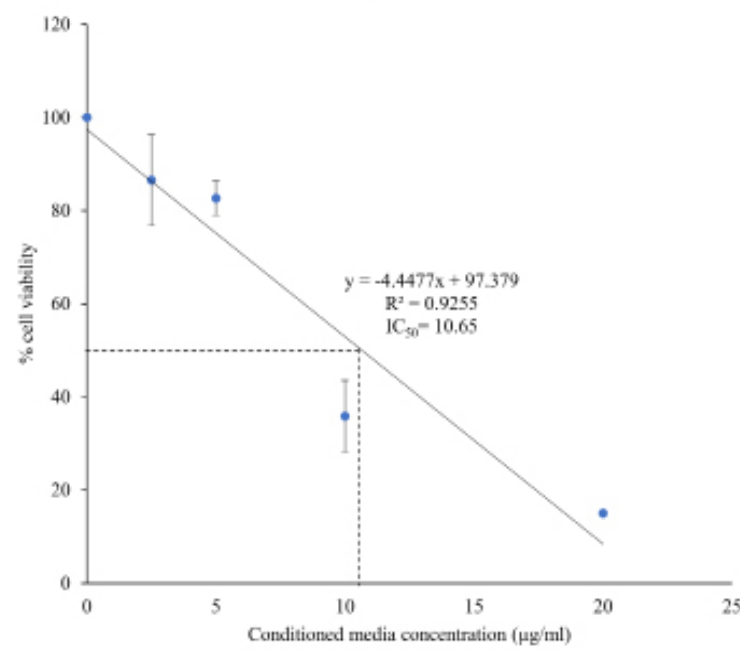

B

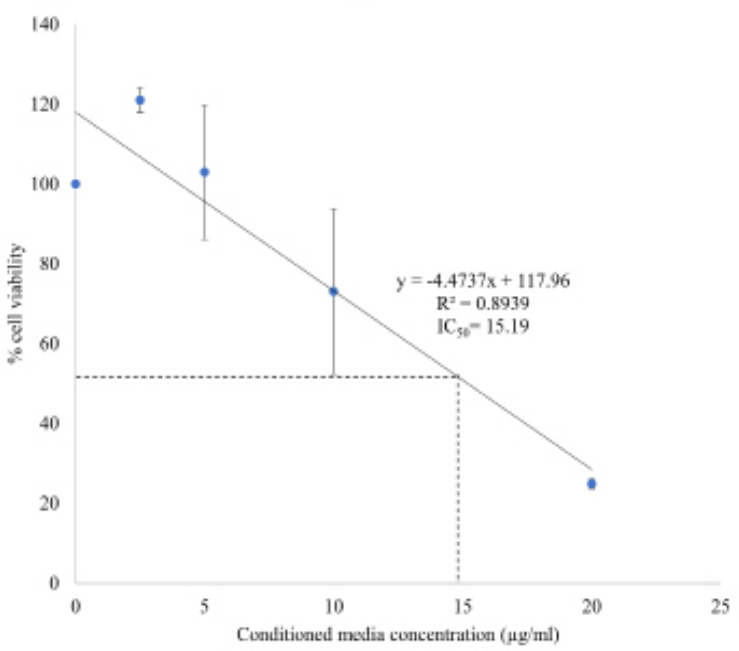

Figure 4. $\mathrm{IC}_{50}$ Concentration of CLF05 and CLG01 against HeLa Cells Using MTT Assay. Cells were incubated with various concentrations of CLF05 and CLG01 and cell survival determined using MTT assays as described in Materials and Methods. Note that both CLF05 and CLG01 exhibited IC50 below $20 \mu \mathrm{g} / \mathrm{ml}$. The results are representative of several experiments performed in duplicate.

\section{Discussion}

There is continued rise in morbidity and mortality associated with cancer, despite the wide range of available treatment options, hence it is imperative to discover and develop new anticancer agents. Our previous work highlighted that animals that thrive in polluted environments, such as crocodiles, cockroaches, water monitor lizards and snakes, may possess anticancer and antibacterial mechanisms to ward off disease (Khan et al., 2019; Jeyamogan et al., 2017; Mosaheb et al., 2018; Soopramanien et al., 2019). In addition to the animal lysates, the faecal and gut microbiota is of particular interest to us, as the gut microbiota is known to play an important role in regulating the behaviour and health of its host (Jeyamogan et al., 2017; Heyde and Ruder,
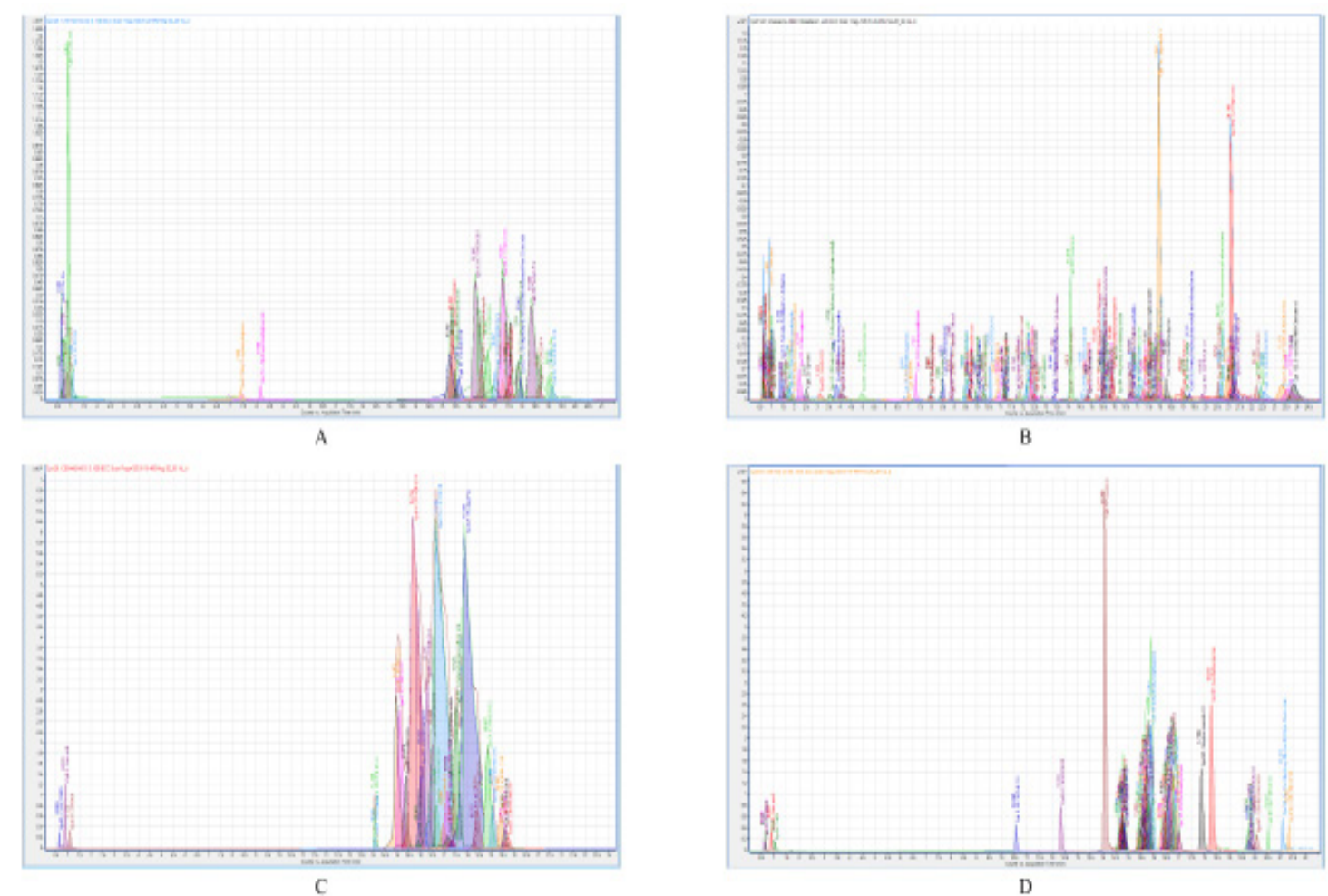

Figure 5. LC-MS Spectra of the Active CM, CLF05 (Bacillus Cereus) and CLG01 (Bacillus Velezensis). Briefly the $\mathrm{CM}$ was subjected to chloroform extraction and the extract was dried under pressure and dissolved in HPLC grade methanol for LC-MS analysis. [A: The spectrum of molecules detected for negative ion polarity from CLF05, B: the spectrum of molecules detected for positive ion polarity from CLF05, C: The spectrum of molecules detected for negative ion polarity from CLG01 and F: the spectrum of molecules detected for positive ion polarity from CLG01]. 
2015; Alarcón et al., 2016). Anticancer effects from avian species remain unexplored and were the subject of present study. A repertoire of bacteria was isolated from both the faecal and gut microbiota of C. livia.

The results revealed that $\mathrm{B}$. cereus and $\mathrm{B}$. velezensis exhibited potent effects against cancer cell lines tested. CM from CLF05 (B. cereus) and CLG01 (B. velezensis) inhibited growth of HeLa cells by more than $40 \%$. Moreover, they inhibited almost $100 \%$ cell growth of cancer cells at a concentration of $10 \mu \mathrm{g} / \mathrm{ml}$ and affected the viability of HeLa cells at IC50 concentrations of 10.65 and $15.19 \mu \mathrm{g} / \mathrm{ml}$, respectively. Furthermore, microscopic images revealed that CLF05 and CLG01 produced damage to HeLa cells. Although LDH release was negligible but $\mathrm{CM}$ affected the integrity human cells indicating that cell death might have resulted from apoptosis. Thus, further experiments are needed to determine apoptosis in treated cells.

Previous work has reported that Bacillus species produce metabolites with anticancer properties, which support our findings (Ferdous et al., 2018). Bioactives such as $\varepsilon$-Poly-L-lysine, Surfactin, Leodoglucomide B, Bacillistatins- 1 and 2 and Mixirins A, B and C synthesised by bacteria have shown to inhibit growth and induce morphological changes in cancer cells (Arnold et al., 1979; Harris and Pierpoint, 2012; Pettit et al., 2009; Tareq et al., 2012; Wu et al., 2017). Previously, anticancer potential of metabolites secreted by B. cereus isolated from soil sample were tested against human liver cell lines and cancer cell lines (Kumar et al., 2014). The results revealed that metabolites from $B$. cereus was cytotoxic to cells with IC50 of $225.4 \mu \mathrm{g} / \mathrm{mL}, 152.2 \mu \mathrm{g} / \mathrm{mL}$, and $152.2 \mu \mathrm{g} / \mathrm{mL}$ against HepG2, Hep2 and Chang liver cells, respectively. These findings suggest that metabolites released by $\mathrm{B}$. cereus exhibit anticancer activity by inducing apoptosis in cancer cells (Kumar et al., 2014).

The LC-MS revealed 111 molecules including dihydroxymelphalan. Dihydroxymelphalan, also known as melphalan is a widely used anticancer drug. It works by causing inter-strand cross-links in DNA strands; resulting in inhibition of DNA and RNA synthesis (Kuczma et al., 2016; Rahaman et al., 2018). Moreover, melphalan upregulates expression of reactive oxygen species which in turn triggers apoptosis in cancer cells by activating caspase-9 (Kuczma et al., 2016; Rahaman et al., 2018). Since melphalan detected in CM from CLF05 induces apoptosis, it supports our speculation that CLF05 induces damage in cancer cells through apoptosis. The other molecules that were elucidated are tazobactam-m1, citric acid, 3-furoic acid, 4-hydroxyphenylglyoxylate, diethanolamine, methionyl-hydroxyproline, bifenazate, diethyltoluamide, metabutethamine, rivastigmine, tropicamide, xylylcarb, and daimuron. These molecules exhibited activities ranging from antimicrobial, hypolipidemic, cholinesterase inhibitor, to inhibitor of fatty acid oxidation, however, their anticancer effects need to be determined (Halstenson et al., 1994; El Baaboua et al., 2018; In et al., 2013; Hall et al., 1985; Stephens et al., 1985; Leung et al., 2005; Deblander et al., 2015; Asano et al., 1997; Alberts et al., 1979; Allen et al., 1970; Ochiai et al., 2007; Sudakin and Osimitz,
2010; deShazo and Nelson, 1979; Khoury et al., 2018; Manny et al., 2001). Similarly, none of the molecules from CLG01 were reported to possess anticancer effects and this will be determined in future studies. Of note, 57 molecules detected from CLF05 and 65 molecules detected from CLG01 respectively remain unknown and are potentially innovative anticancer agents. Moreover, only aerobic culturable bacteria were isolated in this study and future studies are needed to isolate anaerobic bacteria and unculturable bacteria, that might also be a principal resource of anticancer molecules.

In conclusion, for the first time, we have showed that gut and faecal microbiota of avian species are a potential source of anticancer properties. We have elucidated various molecules that could serve as possible drug leads; but further research is needed to achieve these prospects. It will be imperative to investigate anticancer effects of bacteria against other cancer cells. Our results further augment our speculation that animals residing in unsanitary habitats, that are detrimental to humans, maybe in fact a large unexploited repertoire for innovative pharmaceutical drugs.

\section{Author Contribution Statement}

RS and NAK conceived the idea. MS and BNHMN sourced the animals and carried out dissections under the supervision of KS. MS and BNHMN carried out all experiments under the supervision of RS and NAK. MS carried out LC/MS analyses under the supervision of RS. MS prepared the first draft of the manuscript. NAK and RS corrected the manuscript. All authors approved the manuscript.

\section{Acknowledgements}

The work in this paper was supported, in part, by the Open Access Program from the American University of Sharjah. This paper represents the opinions of the author(s) and does not mean to represent the position or opinions of the American University of Sharjah.

\section{Declarations}

Ethics Approval and Consent to Participate: This article does not contain any studies with human participants. The use of animals was approved by Sunway Research Ethics Committee (Research Ethics Approval Code: PGSUNREC 2019/023). We also confirm that all experiments were performed in accordance with relevant guidelines and regulations.

\section{Consent for Publication \\ Not applicable.}

\section{Funding}

The work is supported by the Sunway University, Malaysia.

\section{Conflict of interest}

The authors declare no conflict of interest, financial or otherwise.

Asian Pacific Journal of Cancer Prevention, Vol 22 


\section{References}

Akbar N, Siddiqui R, Iqbal M, Sagathevan K, Khan NA (2018). Gut bacteria of cockroaches are a potential source of antibacterial compound (s). Lett Appl Microbiol, 66, 416-26.

Akbar N, Khan NA, Sagathevan K, et al (2019). Gut bacteria of Cuora amboinensis (turtle) produce broad-spectrum antibacterial molecules. Sci Rep, 9, 1-19.

Alarcón P, González M, Castro É (2016). The role of gut microbiota in the regulation of the immune response. Revista Medica Chile, 144, 910-6.

Ali SM, Siddiqui R, Ong SK, et al (2017). Identification and characterization of antibacterial compound (s) of cockroaches (Periplaneta americana). Appl Microbiol Biotech, 101, 253-86.

Arnold LJ, Dagan A, Gutheil J, Kaplan NO (1979). Antineoplastic activity of poly (L-lysine) with some ascites tumor cells. PNAS, 76, 3246-50.

Chakraborty S, Rahman T (2012). The difficulties in cancer treatment. Ecancermedicalscience, 6, Ed16.

Ferdous U, Shishir M, Khan S, Hoq M (2018). Bacillus spp.: Attractive Sources of Anti-cancer and Anti-proliferative Biomolecules. Microbial Bioactives, 1, 33-45.

Harris F, Pierpoint L (2012). Photodynamic therapy based on 5-aminolevulinic acid and its use as an antimicrobial Agent. Med Res Rev, 32, 1292-1327.

Heyde KC, Ruder WC (2015). Exploring host-microbiome interactions using an in silico model of biomimetic robots and engineered living cells. Sci Rep, 5, 11988.

Khan NA, Soopramanien M, Siddiqui R (2019). Crocodiles and alligators: physicians' answer to cancer?. Curr Oncol, 26, 186.

Kumar MV, Thippeswamy B, Raj PV (2014). Cytotoxicity and anticancer studies of Bacillus cereus and Bacillus pumilus metabolites targeting human cancer cells. Appl Biochem Microbiol, 50, 619-23.

Kuczma M, Ding ZC, Zhou G (2016). Immunostimulatory effects of melphalan and usefulness in adoptive cell therapy with antitumor CD4+ T cells. Crit Rev Immunol, 36, 179-91.

Jeyamogan S, Khan NA, Siddiqui R (2017). Animals living in polluted environments are a potential source of anti-tumor molecule (s). Can Chemother Pharmacol, 80, 919-24.

Jeyamogan S, Khan NA, Sagathevan K, Siddiqui R (2019). Sera/Organ Lysates of selected animals living in polluted environments exhibit cytotoxicity against cancer cell lines. Anti-Cancer Agent Med Chem, 19, 2251-68.

Mosaheb MUWFZ, Khan NA, Siddiqui R (2018). Cockroaches, locusts, and envenomating arthropods: a promising source of antimicrobials. Iran J Basic Med Sci, 21, 873-7.

Pettit GR, Knight JC, Herald DL, et al (2009). Antineoplastic agents. 570. Isolation and structure elucidation of bacillistatins 1 and 2 from a marine Bacillus silvestris. $J$ Nat Product, 72, 366-71.

Rahaman ST, Pentakota R, Vasireddy P (2018). An overview on various types of anticancer drugs and their drug-drug interactions: Melphalan, 5-fluorouracil, and hydrazine. $J$ Pharm Res, 12, 160-7.

Siddiqui R, Jeyamogan S, Ali SM, et al (2017). Crocodiles and alligators: antiamoebic and antitumor compounds of crocodiles. Exp Parasitol, 183, 194-200.

Siddiqui R, Mansoor S, Khan NA (2016). Do crocodiles and alligators hold the key to cancer treatment?. BMJ, 354, i3763.

Soopramanien M, Mungroo MR, Sagathevan KA, Khan NA, Siddiqui R (2019). Invertebrates living in polluted environments are potential source of novel anticancer agents. Mar Pharm J, 23, 1079-89.

Tareq FS, Kim JH, Lee MA, et al (2012). Ieodoglucomides A and
B from a marine-derived bacterium Bacillus licheniformis. Organ Lett, 14, 1464-67.

Wu YS, Ngai SC, Goh BH, et al(2017). Anticancer activities of surfactin and potential application of nanotechnology assisted surfactin delivery. Front Pharmacol, 8, 761.

This work is licensed under a Creative Commons AttributionNon Commercial 4.0 International License. 